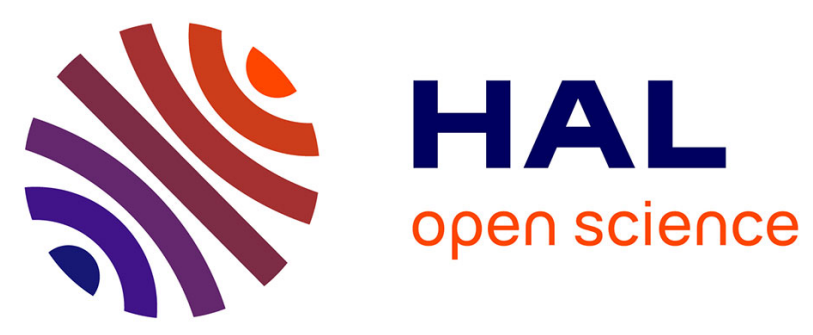

\title{
Induction of apoptosis by thymoquinone in lymphoblastic leukemia Jurkat cells is mediated by a p73-dependent pathway which targets the epigenetic integrator UHRF1
}

Mahmoud Alhosin, Abdurazzag Abusnina, Mayada Achour, Tanveer Sharif, Christian Muller, Jean Peluso, Thierry Chataigneau, Claire Lugnier, Valérie B. Schini-Kerth, Christian Bronner, et al.

\section{- To cite this version:}

Mahmoud Alhosin, Abdurazzag Abusnina, Mayada Achour, Tanveer Sharif, Christian Muller, et al.. Induction of apoptosis by thymoquinone in lymphoblastic leukemia Jurkat cells is mediated by a p73dependent pathway which targets the epigenetic integrator UHRF1. Biochemical Pharmacology, 2010, 79 (9), pp.1251. 10.1016/j.bcp.2009.12.015 . hal-00573917

\section{HAL Id: hal-00573917 https://hal.science/hal-00573917}

Submitted on 5 Mar 2011

HAL is a multi-disciplinary open access archive for the deposit and dissemination of scientific research documents, whether they are published or not. The documents may come from teaching and research institutions in France or abroad, or from public or private research centers.
L'archive ouverte pluridisciplinaire HAL, est destinée au dépôt et à la diffusion de documents scientifiques de niveau recherche, publiés ou non, émanant des établissements d'enseignement et de recherche français ou étrangers, des laboratoires publics ou privés. 


\section{Accepted Manuscript}

Title: Induction of apoptosis by thymoquinone in lymphoblastic leukemia Jurkat cells is mediated by a p73-dependent pathway which targets the epigenetic integrator UHRF1

Authors: Mahmoud Alhosin, Abdurazzag Abusnina, Mayada

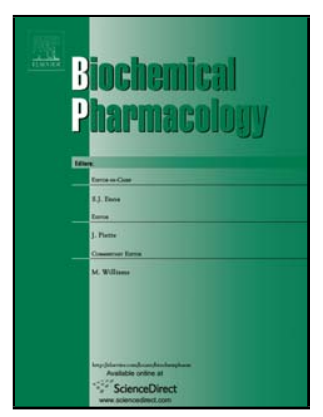

Achour, Tanveer Sharif, Christian Muller, Jean Peluso, Thierry

Chataigneau, Claire Lugnier, Valérie B. Schini-Kerth,

Christian Bronner, Guy Fuhrmann

PII:

S0006-2952(09)01073-9

DOI: doi:10.1016/j.bcp.2009.12.015

Reference:

BCP 10412

To appear in: $\quad B C P$

Received date: $\quad$ 28-10-2009

Revised date: $\quad 11-12-2009$

Accepted date: $\quad$ 14-12-2009

Please cite this article as: Alhosin M, Abusnina A, Achour M, Sharif T, Muller C, Peluso J, Chataigneau T, Lugnier C, Schini-Kerth VB, Bronner C, Fuhrmann G, Induction of apoptosis by thymoquinone in lymphoblastic leukemia Jurkat cells is mediated by a p73-dependent pathway which targets the epigenetic integrator UHRF1, Biochemical Pharmacology (2008), doi:10.1016/j.bcp.2009.12.015

This is a PDF file of an unedited manuscript that has been accepted for publication. As a service to our customers we are providing this early version of the manuscript. The manuscript will undergo copyediting, typesetting, and review of the resulting proof before it is published in its final form. Please note that during the production process errors may be discovered which could affect the content, and all legal disclaimers that apply to the journal pertain. 


\title{
Induction of apoptosis by thymoquinone in lymphoblastic leukemia Jurkat cells is mediated by a p73-dependent pathway which targets the epigenetic integrator UHRF1
}

\author{
Mahmoud Alhosin ${ }^{1,}$, Abdurazzag Abusnina ${ }^{1,}$, Mayada Achour ${ }^{1}$, Tanveer Sharif ${ }^{1}$, \\ Christian Muller $^{2}$, Jean Peluso ${ }^{2}$, Thierry Chataigneau ${ }^{1}$, Claire Lugnier ${ }^{1}$, Valérie B. \\ Schini-Kerth ${ }^{1}$, Christian Bronner ${ }^{1, \#}$ and Guy Fuhrmann ${ }^{1, \#, *}$ \\ ${ }^{1}$ CNRS UMR 7213 Laboratoire de Biophotonique et Pharmacologie, ${ }^{2}$ CNRS UMR \\ 7200 Laboratoire d'Innovation Thérapeutique, Université de Strasbourg, Faculté de \\ Pharmacie, 74 route du Rhin, 67401 Illkirch, France \\ ${ }^{\S}$ Co-equal first author \\ \# Co-equal senior author \\ * Corresponding author: Guy Fuhrmann
}

CNRS UMR 7213

Laboratoire de Biophotonique et Pharmacologie

Faculté de Pharmacie

74 route du Rhin, B.P. 60024,67401 Illkirch

FRANCE

Tel: (33) 368854133

Fax: (33) 368854313

E-mail: guy.fuhrmann@unistra.fr 


\section{ABSTRACT}

The salvage anti-tumoral pathway which implicates the p53-related $p 73$ gene is not yet fully characterized. We therefore attempted to identify the up- and down-stream events involved in the activation of the p73-dependent pro-apoptotic pathway, by focusing on the anti-apoptotic and epigenetic integrator UHRF1 which is essential for cell cycle progression. For this purpose, we analyzed the effects of a known anti-neoplastic drug, thymoquinone (TQ), on the p53-deficient acute lymphoblastic leukemia (ALL) Jurkat cell line. Our results showed that TQ inhibits the proliferation of Jurkat cells and induces G1 cell cycle arrest in a dose-dependent manner. Moreover, TQ treatment triggers programmed cell death, production of reactive oxygen species (ROS) and alteration of the mitochondrial membrane potential $(\Delta \Psi \mathrm{m})$. TQ-induced apoptosis, confirmed by the presence of hypodiploid G0/G1 cells, is associated with a rapid and sharp re-expression of p73 and dose-dependent changes of the levels of caspase- 3 cleaved subunits. These modifications are accompanied by a dramatic down-regulation of UHRF1 and two of its main partners, namely DNMT1 and HDAC1, which are all involved in the epigenetic code regulation. Knockdown of p73 expression restores UHRF1 expression, reactivates cell cycle progression and inhibits TQ-induced apoptosis. Altogether our results showed that TQ mediates its growth inhibitory effects on ALL p53-mutated cells via the activation of a p73-dependent mitochondrial and cell cycle checkpoint signaling pathway which subsequently targets UHRF1.

Keywords: Apoptosis; caspase; thymoquinone; tumor suppressor protein p73; UHRF1. 


\section{Introduction}

The $p 73$ gene produces a protein homolog to $\mathrm{p} 53$ with similar functions [1]. p73 regulates the transcription of several p53 target genes, including the apoptosisregulating gene PUMA, a Bax transactivator, and the cell cycle regulatory genes $p 21^{\text {Wafl/Cipl }}$ [2] and $p 16^{I N K 4 A}$ [3]. Transcriptional activation of these genes leads to the induction of cell-cycle arrest and/or apoptosis [2]. It is therefore expected that many p53-responsive genes could also be targets of p73, especially those genes which respond to DNA damage and could initiate cell cycle arrest and/or apoptosis. This could explain that cells lacking functional p53 have the ability to undergo apoptosis through a p53independent pathway when p73 is expressed [4]. Apart its p53-mimetic activity, p73 is also a major component of specific signaling cascades, like the caspase-independent cell death (CICD) [5].

Under physiological conditions, the basal expression of the $p 73$ gene is kept extremely low and is only up-regulated in response to cellular stress [1]. This explains that, in spite of extensive searches, mutations of the $p 73$ gene are rarely detected in primary tumors [6], but aberrant hypermethylation of the $p 73$ promoter region and subsequent inactivation of the $p 73$ gene have been reported in acute lymphoblastic leukemia (ALL) [7]. The consequences of this hypermethylation and its maintenance are not clearly understood but they likely target the expression of specific genes involved in the DNA damage response. We hypothesized that UHRF1 (Ubiquitin-like, containing P $\underline{H D}$ and $\underline{R} I N G$ Finger domains, 1) could be a major effector of the p73 deregulation, since this nuclear protein is known to be over-expressed in numerous cancer cell lines and tissues [8-11]. 
Several studies have shown that UHRF1 participates in the control of cell proliferation and cell cycle transition from $\mathrm{G} 1$ to $\mathrm{S}$, by regulating the expression of several genes, including $R B 1$ and $p 16^{I N K 4 A}[12,13]$. This suggests that pathological overexpression of UHRF1, by repressing permanently the expression of specific tumor suppressor genes, could induce disorders in the G1/S progression and consequently promote tumor development [10]. In agreement with our hypothesis, it has been shown that the activation of different cell cycle checkpoints during DNA damage-induced apoptosis leads to a down-regulation of UHRF1 [9]; such deregulation has been described to be dependent on the p53/p2 $1^{\mathrm{WAF} 1 / \mathrm{CIP} 1}$ pathway [14]. It should be noted that reduction of UHRF1 expression solely can suppress proliferation and induce apoptosis of cancer cells whose p53 is inactivated [15]. This suggests that UHRF1 functions as a component in the DNA damage response pathways and that it plays a role in the maintenance of genomic stability. In this point of view, accumulating evidences have shown that UHRF1 acts as a multi-modular protein involved in the maintenance of the chromatin status and its propagation during cell division. Indeed, UHRF1 binds to methylated DNA and recruits DNA methyltransferase 1 (DNMT1) and histone

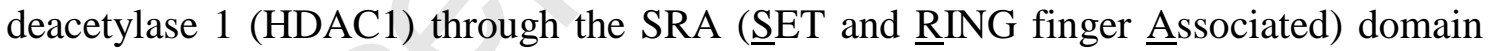
[13,16-19]. These protein-protein interactions precede $S$ phase entry and could be required for cell cycle progression [10,20]. UHRF1 therefore, ensures the crosstalk between DNA methylation and histone modifications, promoting the maintenance of the epigenetic code and its transmission from a mother cell to the descent cells [21]. For these reasons it is suspected that a down-regulation of UHRF1 in response to DNA damage has dramatic consequences on the cell viability. 
A number of studies have shown that thymoquinone (TQ) is a potent cytotoxic and genotoxic drug over a broad range of human cancer cells [22]. It has been suggested that TQ, as a DNA damaging agent, is a potential reactive oxygen species (ROS) producer which exerts its anti-cancer effects by inhibiting cell growth, arresting cell cycle progression and inducing subsequently apoptosis [23-29]. p53-dependent [26] and p53-independent pathways $[23,27]$ have been evidenced to explain the cellular actions of TQ. In HCT-116 colorectal cancer cells, TQ-induced apoptosis involves an upregulation of both $\mathrm{p} 53$ and $\mathrm{p} 21^{\mathrm{WAF} 1 / \mathrm{CIP} 1}$ expressions, concomitantly with a downregulation of the expression of the anti-apoptotic protein Bcl-2 [26]. In p53-null myeloblastic leukemia HL-60 cells [27] and in p53-null osteosarcoma MG63 cells [28], the anti-cancer activities of TQ involve alterations of the $\mathrm{Bax} / \mathrm{Bcl} 2$ ratio and caspase activations, but the precise mechanisms remain unknown.

The aim of the present study is to determine in the p53-deficient Jurkat cell line [30] whether an activation of the $p 73$ gene, via a TQ-induced DNA damage, could target the anti-apoptotic $U H R F 1$ gene with subsequent cell cycle arrest and apoptosis. Our results show that TQ produces intracellular ROS, promotes a DNA damage-related cell cycle arrest and triggers apoptosis through the activation of a p73-dependent mitochondrial and cell cycle signaling pathway, followed by a down-regulation of UHRF1. We hypothesize that this p73-dependent down-regulation of UHRF1 prevents epigenetic code replication and thus hinders the "cancer signature" to be inherited by the daughter cancer cells.

\section{Material and methods}




\subsection{Cell Culture, Treatment and Transfection}

The human leukemic T-cell line Jurkat (clone E6-1) was cultured as previously described [13]. A $100 \mathrm{mM}$ solution of TQ (Sigma-Aldrich, St. Louis, MO, USA) was prepared in 100\% DMSO (DiMethylSulfOxide; Millipore S.A.S., Molsheim, France) and appropriate working concentrations were prepared with the cell culture medium; the final concentration of DMSO was of $0.1 \%$ in both control and treated conditions. Transient transfections of p73 siRNA duplex (sc-36167; Santa Cruz Biotechnologies, Santa Cruz, CA, USA), UHRF1 siRNA duplex (5' GGUCAAUGAGUACGUCGAUdTdT-3'; [13]) or scramble siRNA duplex (5'GGACUCUCGGAUUGUAAGAdTdT-3'; [13]) were performed with lipofectamine 2000 (Invitrogen, Eugene, OR, USA), following the manufacturer's recommendations. Transient transfections with pSG5 or pSG5-UHRF1 plasmid were performed as previously described [31]. Experiments using a specific inhibitor of caspase-3 (ZDEVD-FMK) were carried out according to the manufacturer's instructions (Millipore S.A.S.).

\subsection{Cell proliferation, viability and apoptosis assays}

Cells were seeded on 6-multiwell plates at a density of $2 \times 10^{6}$ cells/well, grown for $24 \mathrm{~h}$ and exposed to TQ at different concentrations for different times. Cell proliferation rate was then assessed by colorimetric assay using the CellTiter 96® AQueous One Solution Cell Proliferation Assay (MTS), following the manufacturer's recommendations (Promega, Charbonnières-les-Bains, France). Cell viability rate was determined by cell 
counting using the trypan blue exclusion method (Invitrogen). The viability rate was obtained by dividing the number of trypan blue-negative cells by the total number of cells. Cell apoptosis rate was assessed by flow cytometer (BD FACSCalibur system, BD Biosciences, San Diego, CA, USA) using the Annexin V-FITC/propidium iodide (PI) apoptosis assay (BD Biosciences), following the manufacturer's recommendations. CellQuest software (BD Biosciences) was used for the analysis of the data. At least 10,000 events were recorded, iteratively increased if possible, and represented as dot plots.

\subsection{Cell cycle phase distribution analysis and quantitation of hypodiploid sub-G0/G1 cell population}

Cells were plated in $80 \mathrm{~cm}^{2}$ culture flasks at a density of $1.5 \times 10^{5}$ cells $/ \mathrm{ml}$, grown for $24 \mathrm{~h}$ and exposed to TQ at different concentrations for different times. Cells were then prepared as previously described [32]. Cellular DNA content was assessed by flow cytometry in either a Guava EasyCyte Plus HP system (Guava Technologies, Hayward, CA, USA) or a BD FACSCalibur system (BD Biosciences).

2.4. Assessment of DNA fragmentation pattern 
Genomic DNA was prepared according to the manufacturer's instructions (Qiagen, Courtaboeuf, France), separated by electrophoresis on a $1 \%$ agarose gel and visualized under UV light with ethidium bromide.

\subsection{Analysis of the production of ROS metabolites}

Treated and untreated cells, seeded at an initial density of $2 \times 10^{6}$ cells/well in 6-well plates, were stained for $30 \mathrm{~min}$ at room temperature with a $1 \mu \mathrm{mol} / \mathrm{l}$ dihydroethidium (DHE; Sigma Aldrich) solution and then subjected to flow cytometric analyses (BD FACSCalibur, BD Biosciences). 10,000 events were recorded per experiment.

\subsection{Mitochondrial membrane potential measurement}

Cells grown as described above, were incubated for $15 \mathrm{~min}$ at $37^{\circ} \mathrm{C}$ in $\mathrm{PBS}$ supplemented with $40 \mathrm{nM}$ of [3,3' - Dihexyloxacarbocyanine iodide] -DiOC6; Sigma Aldrich- and $1 \mu \mathrm{g} / \mathrm{ml} \mathrm{PI}$, followed by FACS analysis (BD FACSCalibur, Becton Dickinson). At least, 5,000 cells were analyzed for each sample.

\subsection{Western blot analysis}

Proteins from cell lysates were extracted, separated on 10-15\% SDS-polyacrylamide gels and transferred to membranes as previously described [13,33]. Immunoblotting was performed by using either a mouse monoclonal anti-p73 antibody (BD Biosciences Pharmingen), a rabbit polyclonal anti-p16 antibody (Proteogenix, Oberhausbergen, 
France), a rabbit polyclonal anti-cleaved caspase-3 antibody (Cell Signaling Technology, Danvers, MA, USA), a mouse monoclonal anti-UHRF1 antibody [31], a mouse monoclonal anti-DNMT1 antibody (Stressgen Biotechnologies, Victoria, BC Canada), a rabbit polyclonal anti-HDAC1 antibody (USBiological, Swampscott, MA, USA), or a mouse monoclonal anti-beta actin antibody (Abcam, Paris, France), according to the manufacturer's instructions. Membranes were then incubated with the appropriate horseradish peroxidase-conjugated secondary antibody. Signals were visualized as previously described [13] and subjected to optical densitometric (OD) quantification by using NIH's Image J software.

\subsection{Statistical analysis}

Data were presented in a bar graph form, expressed as means \pm S.E.M. from at least three independent experiments and statistically subjected to the one-way ANOVA test. Significance levels were defined in accordance with the standard notation.

\section{Results}

\subsection{TQ inhibits cell growth and induces cell cycle arrest of Jurkat cells}

The Jurkat cell line was used to identify and characterize the molecular mechanisms induced by TQ. We first analyzed the effects of TQ on the growth parameters of this cell line. Cell proliferation (Fig. 1A) and cell viability (Fig. 1B) following TQ treatment, were decreased in a concentration-dependent manner. In our experimental 
conditions, calculated concentrations of TQ-induced half-maximal effects on cell proliferation and viability were respectively of $24.2 \pm 0.3 \mu \mathrm{M}$ and $24.3 \pm 0.2 \mu \mathrm{M}$ for $24 \mathrm{~h}$ of treatment. When treated with TQ for $48 \mathrm{~h}$, these values were $23.3 \pm 0.2 \mu \mathrm{M}$ and $23.1 \pm 0.4 \mu \mathrm{M}$ respectively (data not illustrated). These results indicate that Jurkat cells respond to TQ within $24 \mathrm{~h}$ and at the previously published concentrations [24-28].

Because cell growth is a result of the progression of the cells through the different phases of the cell cycle, we next determined the effects of TQ on the cell cycle distribution (Fig. 1C). Slight modifications were already detectable at $10 \mu \mathrm{M}$ of TQ and a significant accumulation of the cell population in G0/G1 phase was observed for higher concentrations. It appears therefore that TQ is able to inhibit the growth of Jurkat cells by promoting cell cycle arrest at the G0/G1 phase.

\subsection{TQ induces apoptosis in Jurkat cells}

We next investigated whether TQ could induce apoptosis in Jurkat cells. As shown in Fig. 2A, increasing concentrations of TQ are associated with increasing number of apoptotic cells. TQ began to trigger apoptosis at $10 \mu \mathrm{M}$ while at $30 \mu \mathrm{M}$, a major proportion of cells was concerned. As expected, the calculated half-maximal effect of TQ on apoptosis was $24.7 \pm 0.3 \mu \mathrm{M}$ ( $24 \mathrm{~h}$ treatment). For $48 \mathrm{~h}$ of treatment with TQ, this value was $23.2 \pm 0.3 \mu \mathrm{M}$ (results not illustrated). Hence, these data were consistent with those obtained from cell proliferation assays. As a next step, cell cycle phase distribution analysis was focused on the detection of specific G0/G1 apoptotic cells; as shown in Fig. 2B, increasing concentrations of TQ led to increasing number of hypodiploid sub-G0/G1 cells. In agreement with these data, the intensity of the genomic 
DNA smears of the TQ-treated Jurkat cells increased in a concentration-dependent manner (Fig. 2C). Finally all these results demonstrate the occurrence of a p53independent DNA damage-related apoptosis in the p53-mutated Jurkat cells, when exposed to TQ.

\subsection{TQ induces the generation of ROS and the breakdown of $\triangle \Psi m$ in Jurkat cells}

We suspected that TQ, like many quinone compounds (e.g. denbinobin), can trigger apoptosis by generating ROS [34], that in turn should induce mitochondrial membrane disruption. We therefore determined by flow cytometry the levels of the DNA intercalating fluorescent marker ethidium which is produced after intracellular oxidation of DHE. As shown in Fig. 3A, cells exposed to increasing concentrations of TQ exhibited enhanced accumulation of intracellular ROS. When compared to untreated cells, a 77\% increase of the fluorescence emitted by the ROS-induced oxidation of DHE was detected in cells treated with $100 \mu \mathrm{M}$ of TQ (Fig. 3A, Fig. 3B). In parallel, the effects of TQ on the mitochondrial membrane potential status were investigated by determining the uptake rate of DiOC6, a mitochondrial specific and voltage-dependent fluorescent dye. Fig. 4 shows that the number of cells, emitting high fluorescence levels, decreases when $20 \mu \mathrm{M}$ or higher concentrations of TQ were used, indicating a dramatic drop of $\Delta \Psi \mathrm{m}$. These results suggest that the DNA-damaging agent TQ induces apoptosis by producing ROS metabolites and triggering mitochondrial membrane potential loss in the p53-mutated Jurkat cells.

\section{4. p73 is up-regulated and UHRF1 is down-regulated in TQ-treated Jurkat cells}


In order to define the nature of the cell cycle checkpoint signaling pathway which could be activated in response to the TQ-induced DNA damage, we first examined the expression status of $\mathrm{p} 73$. In the absence of TQ, the expression of $\mathrm{p} 73$ in Jurkat cells was faintly detectable; however when concentrations of TQ reached $10 \mu \mathrm{M}$, a sharp increase in the expression of p73 was observed after either $24 \mathrm{~h}$ or $48 \mathrm{~h}$ of treatment (Figs. 5A \& 5B). This up-regulation, observed in a concentration-dependent manner, concerned both $\alpha$ and $\beta$ isoforms of $p 73$ and was correlated with increasing expression levels of the tumor suppressor protein $\mathrm{p} 16^{\mathrm{INK} 4 \mathrm{~A}}$ (Fig. 5A). Interestingly, p73 re-expression was accompanied by a transient over-expression of caspase-3 cleaved subunits, only observed in cells exposed to $10 \mu \mathrm{M}$ of TQ. At higher concentrations of TQ however, caspase-3, became undetectable in their active conformation (Fig. 5A).

There are several lines of evidence that UHRF1 deregulation may impair the control of G1/S transition during cell cycle checkpoint activation [8, 9, 14]. Since such activation is known to occur during the DNA damage-related apoptosis of TQ [23-26], we analyzed the expression levels of UHRF1 and its partners DNMT1 and HDAC1 in TQ-treated Jurkat cells. As shown in Fig. 5A, treatment of Jurkat cells with TQ (up to $10 \mu \mathrm{M})$ resulted in a faint decrease in the expression levels of UHRF1 and DNMT1. In contrast, the expression levels of HDAC1 appeared to increase. However at higher concentrations of TQ, all the three proteins became undetectable. Taken together, these results also observed after $48 \mathrm{~h}$ of TQ treatment (Fig. 5B), indicate that TQ-induced apoptosis in Jurkat cells is associated with an activation of the cell cycle checkpoint regulator $\mathrm{p} 73$ and a down-regulation of the UHRF1/DNMT1/HDAC1 complex. 
3.5. TQ rapidly induces apoptosis, cell cycle arrest and deregulation of p73 and UHRF1 expressions in Jurkat cells

In order to determine more precisely the chronology of the cellular and molecular events induced by TQ, we analyzed the time-course effects of TQ on Jurkat cells, at a concentration corresponding to its half-maximal activity $(25 \mu \mathrm{M})$. As shown in Fig. 6A and $6 \mathrm{~B}$, a notable number of cells in apoptosis appeared within $3 \mathrm{~h}$ of treatment, suggesting that the cell cycle progression is rapidly slowing down after TQ exposition. Accordingly, significant accumulation of cells in G0/G1 phase could be evidenced after $6 \mathrm{~h}$ of treatment (Fig. 6C). Interestingly, increased levels of p73 could be detected within 3h of TQ exposition (Fig. 6D); this up-regulation is accompanied with a progressive down-regulation of UHRF1, in association with the appearance of a lower molecular weight form (Fig. 6D). Moreover the up-regulation of p73 was also correlated with a marked over-expression of caspase-3 cleaved subunits. Thus, for the concentrations of TQ above $10 \mu \mathrm{M}$ that showed an absence of cleaved caspase- 3 after $24 \mathrm{~h}$ or $48 \mathrm{~h}$ (Figs. 5 A \& 5B), there was an increased expression of the activated caspase-3 in the early hours of treatment. These results suggest that TQ-induced apoptosis is linked to a rapid deregulation of p73 and UHRF1 expressions in Jurkat cells.

\subsection{Knockdown of p73 counteracts TQ-induced UHRF1 down-regulation, cell cycle arrest and apoptosis in Jurkat cells}

To determine whether p73 could act in Jurkat cells as a main regulator of the apoptotic signaling pathway activated by TQ, we attempted an acute depletion of p73 by 
transfecting TQ-treated cells with specific siRNA against p73. As shown in Fig. 7A, p73 knockdown restored UHRF1 expression at levels similar to those observed for untreated cells; accordingly a normalization of the expression level ratio of the two proteins could be evidenced (Fig. 7B). The knockdown of p73 also allowed reactivation of cell cycle progression since the percentage of the cell populations in G0/G1 and S phase is significantly inversed when compared to that of TQ-treated cells transfected with scramble siRNA (Fig. 7C). Consistently, a significant decrease in the number of apoptotic cells could be observed (Fig. 7D). These data clearly demonstrated that UHRF1 is down-stream of p73 in the TQ-induced apoptotic pathway. In order to address unambiguously whether UHRF1 is targeted by p73 and is involved in the apoptotic process, we further determined the direct relationships between a p73 deregulation, modulations of UHRF1 expression and apoptosis in Jurkat cells, in the absence of TQ. As shown in Fig. 8A, siRNA-induced decrease of the basal expression levels of p73 upregulated UHRF1 expression. Moreover UHRF1 siRNA which induced the decrease of the basal expression levels of UHRF1 (Fig. 8B) significantly increased the number of apoptotic cells when compared to the controls (Fig. 8C), showing that UHRF1 exhibits anti-apoptotic properties. Altogether these results indicate that TQ triggers apoptosis in Jurkat cells through a DNA damage response involving the activation of the tumor suppressor protein $\mathrm{p} 73$, which is able to induce a downregulation of the expression of the anti-apoptotic protein UHRF1.

3.7. UHRF1 down-regulation in TQ-treated Jurkat cells leads to apoptosis via a caspase-dependent mechanism 
We suspected that TQ, at a concentration corresponding to its half-maximal effects, could activate a p73-dependent caspase-dependent pathway which could then trigger the down-regulation of UHRF1 and subsequently apoptosis. We therefore examined the effects of a caspase-3 specific inhibitor on TQ activity in Jurkat cells. Indeed, Z-DEVDFMK was able to counteract the decrease of UHRF1 expression (Fig. 9A) and the apoptotic process (Fig. 9B) induced by $25 \mu \mathrm{M}$ of TQ. Moreover, an acute overexpression of UHRF1 after TQ treatment can partially rescue the cells from apoptosis, thus mimicking the effects of a caspase-3 inhibitor (Fig. 9C). The results suggest that the TQ-activation of the p73-dependent mitochondrial caspase-dependent pathway induces UHRF1 down-regulation which explains, at least in part, the observed apoptosis.

\section{Discussion}

It has been reported that the pro-apoptotic activity of TQ on cancer cells occurs in p53 wild-type cells through an up-regulation of both the tumor suppressor protein p53 and the cyclin dependent kinase inhibitor $\mathrm{p} 21^{\text {Waf1/Cip1 }}$ which in turn induces $\mathrm{G} 1$ cell cycle arrest and apoptosis [26]. In p53-null cells however, the molecular mechanisms leading to TQ-induced mitochondrial reactivity are poorly documented.

The present study demonstrates that TQ triggers apoptosis in the p53-deficient Jurkat cell line through the production of ROS and the activation of the cell cycle checkpoint regulator p73. Accordingly it has been shown that ROS production can be an efficient activator of p73 expression [35]. On the other hand, different point mutations in the p53 gene have been evidenced in Jurkat cells, mostly at the C-terminal 
basic domain [30], which is required for the activation of the $p 21^{\text {Wafl/Cipl }}$ gene, for cell cycle arrest and for apoptosis [36]. Thus, the p53-dependent pathway is not involved in the effects of the ROS producer TQ on Jurkat cells.

Similarly to $\mathrm{p} 53$, the structural and functional homolog $\mathrm{p} 73$ can promote cell cycle arrest and apoptosis when over-expressed [4]. Moreover, it has been reported that cellular stress signals can induce endogenous expression of p73 in p53 null or mutant cells, engaging a p53-independent apoptotic pathway [37,38]. Accordingly p73 seems to act as a cellular gatekeeper by preventing the proliferation of TQ-exposed Jurkat cells; obviously the sharp re-expression of p73 that we observed in response to TQ, triggers G0/G1 cell cycle arrest and apoptosis. This cell reactivity is likely a down-stream effect of p73 since the knockdown of $\mathrm{p} 73$ in TQ-treated cells restored cell cycle progression and proliferation. It has been observed that early increased expression of p73 in response to cell stress is a consequence of an accumulation at the protein level [39]. It could therefore be hypothesized that the proteasome-mediated proteolytic degradation of p73 is rapidly blocked after TQ-treatment, leading to a stabilization of the protein.

To determine whether the cell cycle checkpoint regulator p73 possesses an operative activity, we analyzed the expression of some of its down-stream effectors in TQ-treated Jurkat cells. Interestingly, a transient TQ concentration-dependent upregulation of caspase 3 cleaved subunits has been shown. First of all, this suggests that TQ exerts its apoptotic activity through caspase-dependent and caspase-independent pathways. p73, like p53, is known to promote the activation of caspases [2]. However, only p73 is involved in a caspase-independent cell death (CICD), which protects cells from aneuploidy by inducing their death when chromosome missegregation occurs [5]. Interestingly it has been observed that the switch from a caspase-dependent to a 
caspase-independent pathway allows the progression from a specific cell death state to another [40]. Jurkat cells treated with high concentrations of TQ likely switch to a particular cell death program which involves the p73-dependent CICD pathway.

We have previously shown in HCT116 cells, a colon cancer cell line, that the activation of the p53-dependent $\mathrm{p} 21^{\text {Wafl/Cip1 }}$ pathway is able to down-regulate UHRF1 [14]. Here we show in Jurkat cells, the most abundant known source of UHRF1 ([31]; personal laboratory observations), that a p73-dependent pathway also regulates UHRF1. Indeed, TQ induces the activation of the cell cycle checkpoint regulator p73, which in turn represses UHRF1 expression in the p53 mutant Jurkat cells. The knockdown of p73 in either untreated or TQ-treated cells modulates UHRF1 expression, indicating that UHRF1 is a down-stream effector of p73 in this cell type. Our data also show that TQ down-regulates DNMT1, which is not surprising considering that DNMT1 is a privileged partner of UHRF1 [13]. Otherwise the variations of HDAC1 expression levels after TQ treatment, at least during the first $24 \mathrm{~h}$, remain to be elucidated. Interfering effects between direct and indirect actions of TQ could however be invoked.

We have previously observed that UHRF1 reduction after activation of the p53dependent pathway is consecutive of both a transcriptional suppression and a protein degradation enhancement [14]; this suggests that the p73-dependent down-regulation of UHRF1 we evidenced, likely results from the same processes. Accordingly the lower molecular weight form we observed within few hours after TQ-treatment could be related to increased UHRF1 degradation after caspase activation. Indeed a specific inhibitor of caspase-3 can recover UHRF1 expression and rescue cells from apoptosis induced by TQ. Interestingly it has been shown that repression of UHRF1 expression after treatment with different inducers of cell cycle checkpoints regulators is associated 
with cell cycle arrest in G0/G1 and cell proliferation inhibition [9]. Although accumulating data have highlighted a correlation between the reduction of UHRF1 expression and cell cycle arrest or apoptosis, the molecular mechanisms which clearly explains this correlation remains unknown [10]. In view of the important role that the epigenetic integrator UHRF1 plays in the maintenance of the chromatin status, its down-regulation should necessarily lead to the loss of genome integrity and cell death. Accordingly, we observed that UHRF1 knockdown in untreated cells, as well as an acute overexpression of UHRF1 in TQ-treated cells, have direct incidences of the cell apoptosis rate. UHRF1 appears therefore to have in our experimental settings antiapoptotic properties, in agreement with previous observations [10,15,21]. One interesting idea therefore is that preventing the epigenetic code to be replicated after UHRF1 deregulation leads to the activation of an apoptotic pathway. But this hypothesis needs further investigations.

In conclusion, this is the first report which shows that a natural compound induces apoptosis by acting on the epigenetic integrator UHRF1. By using a p53 mutant cell line, we have shown that TQ produces ROS metabolites and acts through a p73dependent mitochondrial pathway which targets UHRF1 and likely DNMT1. This pathway could involve either a caspase-dependent or caspase-independent activation (see graphical abstract). However the role of CICD on UHRF1 expression and activity remains unclear and its study is currently under investigation. Our data also highlight a new property of TQ which could be used to prevent the epigenetic code to be transmitted from a mother cell to the daughter cells.

\section{Acknowledgments}


This study was supported by grants of the Ligue contre le Cancer, Comité du Haut-Rhin, France. Mahmoud Alhosin and Mayada Achour are supported by fellowships from the Syrian Higher Education Ministry. Abdurazzag Abusnina is supported by a fellowship from the Libyan Higher Education Ministry. Tanveer Sharif is supported by a fellowship from the Higher Education Commission of Pakistan. The authors would like to thank Claudine Ebel (IGBMC, Illkirch, France) for her scientific expertise and Emmanuelle Georgi for skilled technical assistance.

\section{References}

[1] Kaghad M, Bonnet H, Yang A, Creancier L, Biscan JC, Valent A, et al. Monoallelically expressed gene related to p53 at 1p36, a region frequently deleted in neuroblastoma and other human cancers. Cell 1997;90:809-19.

[2] Levrero M, De Laurenzi V, Costanzo A, Gong J, Wang JY, Melino G. The p53/p63/p73 family of transcription factors: overlapping and distinct functions. J Cell Sci 2000;113:1661-70.

[3] Boominathan L. Some facts and thoughts: p73 as a tumor suppressor gene in the network of tumor suppressors. Mol Cancer 2007;6:1-8.

[4] Jost CA, Marin MC, Kaelin WG. p73 is a human p53-related protein that can induce apoptosis. Nature 1997;389:191-4.

[5] Kitagawa K, Niikura Y. Caspase-independent mitotic death (CIMD). Cell Cycle 2008;7:1001-5.

[6] Ikawa S, Nakagawara A, Ikawa Y. p53 family genes: structural comparison, expression and mutation. Cell Death Differ 1999;12:1154-61.

[7] Corn PG, Kuerbitz SJ, van Noesel MM, Esteller M, Compitello N, Baylin SB, et al. Transcriptional silencing of the p73 gene in acute lymphoblastic leukemia and Burkitt's lymphoma is associated with 5' CpG island methylation. Cancer Res 1999;59:3352-6. 
[8] Mousli M, Hopfner R, Abbady AQ, Monté D, Jeanblanc M, Oudet P, et al. ICBP90 belongs to a new family of proteins with an expression that is deregulated in cancer cells. Br J Cancer 2003;89:120-7.

[9] Jenkins Y, Markovtsov V, Lang W, Sharma P, Pearsall D, Warner J, et al. Critical role of the ubiquitin ligase activity of UHRF1, a nuclear RING finger protein, in tumor cell growth. Mol Biol Cell 2005;16:5621-9.

[10] Bronner C, Achour M, Arima Y, Chataigneau T, Saya H, Schini-Kerth VB. The UHRF family: oncogenes that are drugable targets for cancer therapy in the near future? Pharmacol Ther 2007;115:419-34.

[11] Unoki M, Kelly JD, Neal DE, Ponder BAJ, Nakamura Y, Hamamoto R. UHRF1 is a novel molecular marker for diagnosis and the prognosis of bladder cancer. Br J Cancer 2009;101:98-105.

[12] Jeanblanc M, Mousli M, Hopfner R, Bathami K, Martinet N, Abbady AQ, et al. The retinoblastoma gene and its product are targeted by ICBP90: a key mechanism in the G1/S transition during the cell cycle. Oncogene 2005;24:7337-45.

[13] Achour M, Jacq X, Rondé P, Alhosin M, Charlot C, Chataigneau T, et al. The interaction of the SRA domain of ICBP90 with a novel domain of DNMT1 is involved in the regulation of VEGF gene expression. Oncogene 2008;27:2187-97.

[14] Arima Y, Hirota T, Bronner C, Mousli M, Fujiwara T, Niwa S, et al. Downregulation of nuclear protein ICBP90 by p53/p21Cip1Waf1-dependent DNA-damage checkpoint signals contributes to cell cycle arrest at G1/S transition. Genes Cells 2004;9:131-42.

[15] Abbady AQ, Bronner C, Trotzier MA, Hopfner R, Bathami K, Muller CD, et al. ICBP90 expression is downregulated in apoptosis-induced Jurkat cells. Ann NY Acad Sci 2003;1010:300-3.

[16] Unoki M, Nishidate T, Nakamura Y. ICBP90, an E2F-1 target, recruits HDAC1 and binds to methyl-CpG through its SRA domain. Oncogene 2004;23:7601-10.

[17] Citterio E, Papait R, Nicassio F, Vecchi M, Gomiero P, Mantovani R, et al. Np95 is a histone-binding protein endowed with ubiquitin ligase activity. Mol Cell Biol 2004;24:2526-35. 
[18] Bostick M, Kim JK, Estève PO, Clark A, Pradhan S, Jacobsen SE. UHRF1 plays a role in maintaining DNA methylation in mammalian cells. Science 2007;317:1760-4.

[19] Sharif J, Muto M, Takebayashi S, Suetake I, Iwamatsu A, Endo TA, et al. The SRA protein Np95 mediates epigenetic inheritance by recruiting Dnmt1 to methylated DNA. Nature 2007;450:908-12.

[20] Milutinovic S, Zhuang Q, Niveleau A, Szyf M. Epigenomic stress response. Knockdown of DNA methyltransferase 1 triggers an intra-S-phase arrest of DNA replication and induction of stress response genes. J Biol Chem 2003;278:14985-95.

[21] Unoki M, Brunet J, Mousli M. Drug discovery targeting epigenetic codes: the great potential of UHRF1, which links DNA methylation and histone modifications, as a drug target in cancers and toxoplasmosis. Biochem Pharmacol 2009;78:1279-88.

[22] Gali-Muhtasib H, Roessner A, Schneider-Stock R. Thymoquinone: a promising anti-cancer drug from natural sources. Int J Biochem Cell Biol 2006;38:1249-53.

[23] Worthen DR, Ghosheh OA, Crooks PA. The in vitro anti-tumor activity of some crude and purified components of blackseed, Nigella sativa L. Anticancer Res 1998;18:1527-32.

[24] Shoieb AM, Elgayyar M, Dudrick PS, Bell JL, Tithof PK. In vitro inhibition of growth and induction of apoptosis in cancer cell lines by thymoquinone. Int $\mathrm{J}$ Oncol 2003;22:107-13.

[25] Gali-Muhtasib HU, Abou Kheir WG, Kheir LA, Darwiche N, Crooks PA. Molecular pathway for thymoquinone-induced cell-cycle arrest and apoptosis in neoplastic keratinocytes. Anticancer Drugs 2004;15:389-99.

[26] Gali-Muhtasib H, Diab-Assaf M, Boltze C, Al-Hmaira J, Hartig R, Roessner A, et al. Thymoquinone extracted from black seed triggers apoptotic cell death in human colorectal cancer cells via a p53-dependent mechanism. Int J Oncol 2004;25:857-66.

[27] El-Mahdy MA, Zhu Q, Wang QE, Wani G, Wani AA. Thymoquinone induces apoptosis through activation of caspase-8 and mitochondrial events in p53-null myeloblastic leukemia HL-60 cells. Int J Cancer 2005;117:409-17. 
[28] Roepke M, Diestel A, Bajbouj K, Walluscheck D, Schonfeld P, Roessner A, et al. Lack of p53 augments thymoquinone-induced apoptosis and caspase activation in human osteosarcoma cells. Cancer Biol Ther 2007;6:160-9.

[29] Gali-Muhtasib H, Kuester D, Mawrin C, Bajbouj K, Diestel A, Ocker M, et al. Thymoquinone triggers inactivation of the stress response pathway sensor CHEK1 and contributes to apoptosis in colorectal cancer cells. Cancer Res 2008;68:5609-18.

[30] Cheng J, Haas M. Frequent mutations in the p53 tumor suppressor gene in human leukemia T-cell lines. Mol Cell Biol 1990;10:5502-9.

[31] Hopfner R, Mousli M, Jeltsch JM, Voulgaris A, Lutz Y, Marin C, et al. ICBP90, a novel human CCAAT binding protein, involved in the regulation of topoisomerase II $\alpha$ expression. Cancer Res 2000;60:121-8.

[32] Sharif T, Auger C, Bronner C, Alhosin M, Klein T, Etienne-Selloum N, et al. Selective proapoptotic activity of polyphenols from red wine on teratocarcinoma cell, a model of cancer stem-like cell. Invest New Drugs 2009; in press.

[33] Fuhrmann G, Sylvester I, Schöler HR. Repression of Oct-4 during embryonic cell differentiation correlates with the appearance of TRIF, a transiently induced DNAbinding factor. Cell Mol Biol 1999;45:717-24.

[34] Sánchez-Duffhues G, Calzado MA, de Vinuesa AG, Appendino G, Fiebich BL, Loock U, et al. Denbinobin inhibits nuclear factor-kappaB and induces apoptosis via reactive oxygen species generation in human leukemic cells. Biochem Pharmacol 2009;77:1401-9.

[35] Singh M, Sharma H, Singh N. Hydrogen peroxide induces apoptosis in HeLa cells through mitochondrial pathway. Mitochondrion 2007;7:367-73.

[36] Zhu J, Zhang S, Jiang J, Chen X. Definition of the p53 functional domains necessary for inducing apoptosis. J Biol Chem 2000;275:39927-34.

[37] Zaika A, Irwin M, Sansome C, Moll UM. Oncogenes induce and activate endogenous p73 protein. J Biol Chem 2001;276:11310-6.

[38] Willis AC, Pipes T, Zhu J, Chen X. p73 can suppress the proliferation of cells that express mutant p53. Oncogene 2003;22:5481-95. 
[39] Irwin MS, Kondo K, Marin MC, Cheng LS, Hahn WC, Kaelin WG. Chemosensitivity linked to p73 function. Cancer Cell 2003;3:403-10.

[40] Rebbaa A, Zheng X, Chou PM, Mirkin BL. Caspase inhibition switches doxorubicin-induced apoptosis to senescence. Oncogene 2003;22:2805-11. 


\section{Figure captions}

Fig. 1. Concentration-dependent effects of TQ on proliferation, cell viability and cell cycle of Jurkat cells. Cells were exposed to TQ at the indicated concentrations and incubated for $24 \mathrm{~h}$. (A) Cell proliferation rate was assessed by colorimetry using the MTS assay. (B) Cell viability rate was assessed by cell counting using trypan blue dye exclusion assay. The absolute value obtained for each TQ-treated sample is expressed in a second step as percent relative to the corresponding absolute value obtained for the untreated sample and set at 100. (C) Cell cycle distribution was assessed by a capillary cytometry detection assay. Cell number in G0/G1, S or G2/M phase was determined and expressed as percent relative to the total cell number. Values are means \pm S.E.M. of three experiments $(\mathrm{n}=3)$; statistically significant: $* *, p<0.01$; ***, $p<0.001$ (versus the corresponding untreated group).

Fig. 2. Concentration-dependent apoptosis induced by TQ in Jurkat cells. Cells were exposed to TQ at the indicated concentrations and incubated for 24h. (A) Cell apoptosis rate was assessed by capillary cytometry using the Annexin V-FITC staining assay. The number of apoptotic cells is expressed as percent relative to the total cell number. Values are means $+/-$ S.E.M. of three experiments $(\mathrm{n}=3)$; statistically significant: ${ }^{* * *}, p$ $<0.001$ (versus untreated group). (B) Hypodiploid sub-G0/G1 cell rate was assessed by cytometry detection assay. Cell number was determined and expressed as percent relative to the total cell number. Values are means \pm S.E.M. of three experiments $(n=3)$; statistically significant: $*, p<0.05 ; * * *, p<0.001$ (versus untreated group). 
Genomic DNA fragmentation was analyzed on an agarose gel, as described in "Material and methods". The observed patterns are representative of three different experiments.

Fig. 3. Concentration-dependent ROS production induced by TQ in Jurkat cells. Cells were exposed to TQ at the indicated concentrations and incubated for $24 \mathrm{~h}$. ROS accumulation was assessed by flow cytometry after DHE incubation. (A) shows in each histogram the levels of fluorescence. (B) shows the overlapping fluorescence curves obtained for untreated and TQ-treated $(100 \mu \mathrm{M})$ cells. The data are representative of three independent experiments.

Fig. 4. Concentration-dependent $\Delta \Psi \mathrm{m}$ disruption induced by TQ in Jurkat cells. Cells were exposed to TQ at the indicated concentrations and incubated for $24 \mathrm{~h} . \Delta \Psi \mathrm{m}$ alteration was assessed by flow cytometry using the DiOC6 staining assay. The percentage of damaged cells with depolarized mitochondrial membranes is indicated in each histogram. The results are representative of three independent experiments.

Fig. 5. Effects of TQ on UHRF1, DNMT1, HDAC1, p73, p16 and cleaved caspase-3 expressions in Jurkat cells. Cells were exposed to TQ at the indicated concentrations and incubated for $24 \mathrm{~h}$ (A) or $48 \mathrm{~h}$ (B). Immunoblotting analyses were performed as described in "Material and methods" with the corresponding antibodies. Specific bands were detected with their expected apparent molecular weight. The data are representative of at least three independent experiments. 
Fig. 6. Time-course of the effects of TQ on the number of apoptotic cells, cell cycle distribution and p73, UHRF1 and cleaved caspase-3 expressions in Jurkat cells. Cells were exposed to $25 \mu \mathrm{M}$ of TQ for the indicated times. (A) shows the results of a representative apoptosis assay, as explained in the legend of Fig. 2A. Cells of the lower left quadrant are viable; cells of the lower right quadrant are in apoptosis. The number of cells in apoptosis, expressed as percentage relative to the total cell number, is indicated. (B) recapitulates the percentage of cells in apoptosis. Values are means \pm S.E.M. of three experiments $(\mathrm{n}=3)$; statistically significant: **, $p<0.01 ; * * *, p<0.001$ (versus untreated group). (C) shows the cell cycle distribution, as explained in the legend of Fig. 1C. Values are means \pm S.E.M. of three experiments $(n=3)$; statistically significant: $* * *, p<0.001$ (versus the corresponding untreated group). (D) shows representative immunoblotting results, as explained in the legend of Fig. 5.

Fig. 7. Effects of p73 knockdown on TQ activity in Jurkat cells. Untransfected cells (2; TQ), scramble siRNA (80 pmol) transfected cells (3; TQ + scr. siRNA) or p73 siRNA (80 pmol) transfected cells (4; TQ + siRNA p73), seeded at a density of $2 \times 10^{5}$ cells $/ \mathrm{ml}$ were grown $18 \mathrm{~h}$ before exposure to $10 \mu \mathrm{M}$ TQ and further cultured for $54 \mathrm{~h}$. As a control, untransfected cells were cultivated without TQ for 72h (1; Control). (A) shows representative immunoblotting results, as explained in the legend of Fig. 5. (B) shows UHRF1/p73 expression level ratio, determined as described in "Material and methods". (C) shows the cell cycle distribution, as explained in the legend of Fig. 1C. (D) shows the percentage of cells in apoptosis, as explained in Fig. 2A. Values are means \pm S.E.M. of three experiments $(\mathrm{n}=3)$; statistically significant: *, $p<0.05$; **, $p<0.01$; ***, $p<$ 
0.001 (versus the corresponding cell condition 1 ); ${ }^{\circ \circ}, p<0.01$ (versus the corresponding cell condition 3).

Fig. 8. Direct relationships between p73 knockdown, UHRF1 deregulation and apoptosis in Jurkat cells. Cells were seeded at a density of $2 \times 10^{5}$ cells $/ \mathrm{ml}$ and grown after different transfection treatments for 48h. (A) and (B) show representative immunoblotting results, as explained in the legend of Fig. 5, and obtained with protein extracts of untransfected cells (control) or cells transfected with 80 pmol of either a scramble siRNA, a siRNA against p73 or a siRNA against UHRF1. (C) shows the percentage of cells in apoptosis after the different treatments, as explained in legend of Fig. 2A. Values are means \pm S.E.M. of three experiments $(n=3)$; statistically significant: $* * *, p<0.001$ (versus control); ${ }^{\circ \circ}, p<0.001$ (versus scramble siRNA).

Fig. 9. Rescue effects after treatment with a caspase-3 inhibitor or an acute overexpression of UHRF1 on TQ-induced apoptosis of Jurkat cells. (A) shows representative immunoblotting results, as explained in the legend of Fig. 5, and obtained with protein extracts of cells, seeded at a density of $2 \times 10^{5}$ cells $/ \mathrm{ml}$, exposed or not after $24 \mathrm{~h}$ to the caspase-3 inhibitor Z-DEVD-FMK for $1 \mathrm{~h}$ and then grown for further $6 \mathrm{~h}$ in the presence or absence of $25 \mu \mathrm{M}$ of TQ. (B) shows the percentage of cells in apoptosis after the different treatments, as explained in the legend of Fig. 2A. Values are means \pm S.E.M. of three experiments $(\mathrm{n}=3)$; statistically significant: **, $p<0.01$; ***, $p<0.001$ (versus control); ${ }^{\circ}, p<0.05$ (versus TQ). (C) shows the apoptosis rate, as explained in the legend of Fig. 2A. Cells, seeded at a density of $2 \times 10^{5}$ cells $/ \mathrm{ml}$, transfected or not after 24h with $6 \mu \mathrm{g}$ of either a pSG5 or pSG5-UHRF1 plasmid for 24h, were grown for 
further $6 \mathrm{~h}$ in the presence or absence of $25 \mu \mathrm{M}$ of TQ. Values are means \pm S.E.M. of three experiments $(\mathrm{n}=3)$; statistically significant: $* * *, p<0.001$ (versus control); ${ }^{\circ}, p<$ 0.05 (versus TQ + pSG5). 


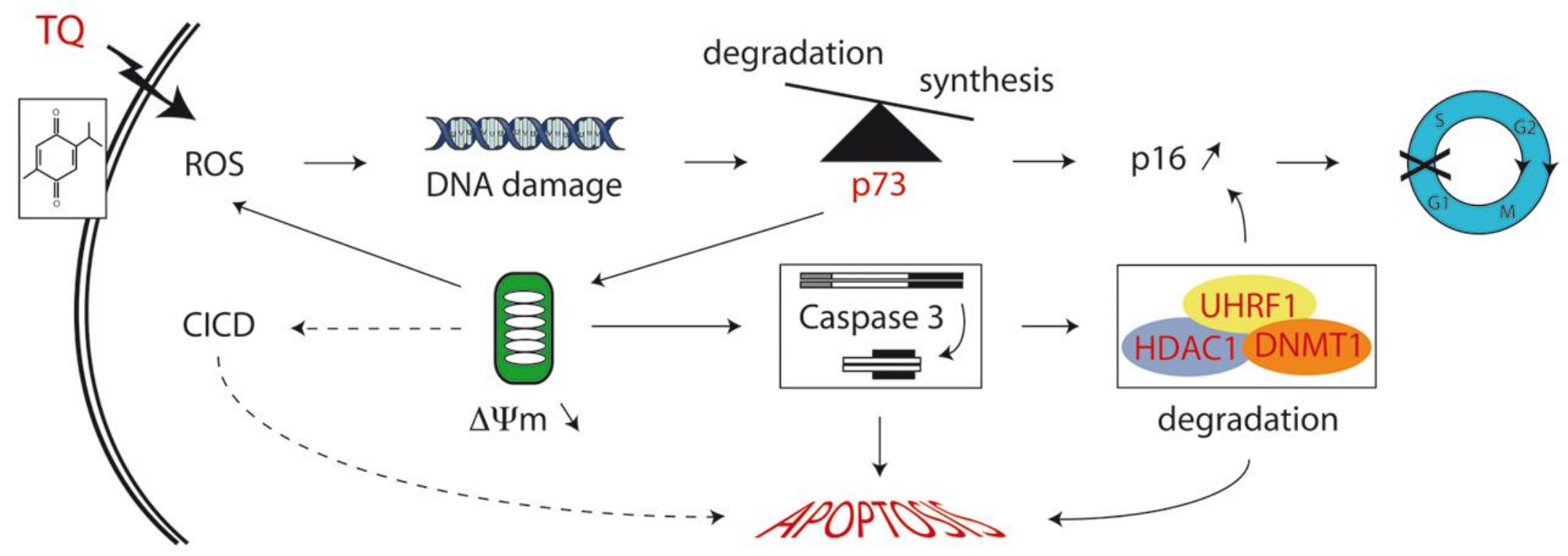

Hypothetical model of TQ p53-independent apoptotic activity involving a caspase-dependent or -independent pathway 
A

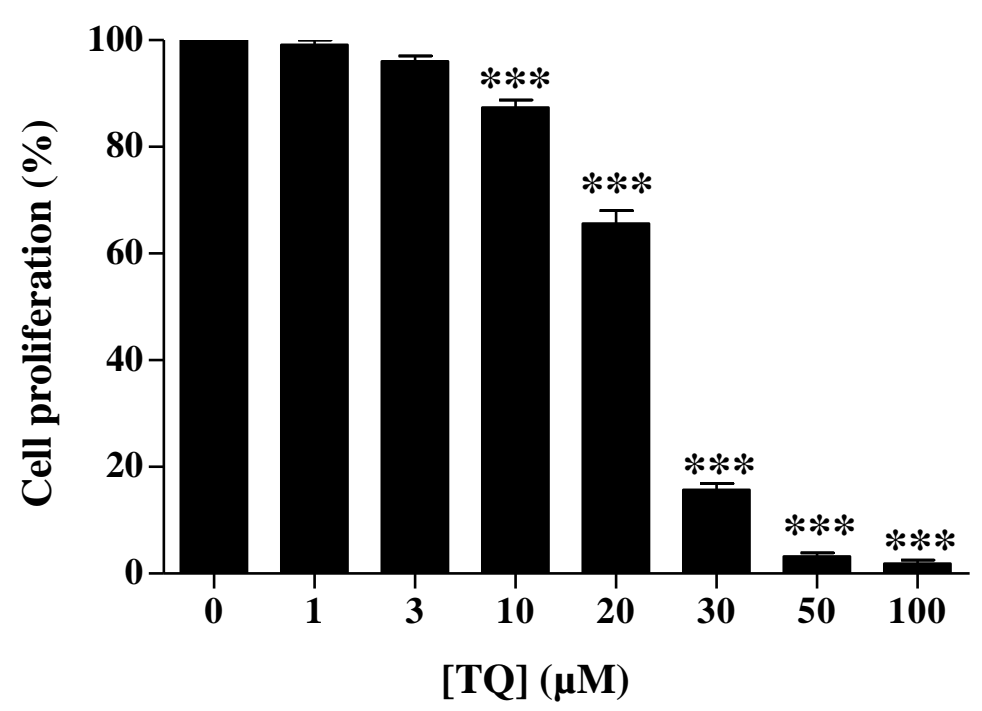

B

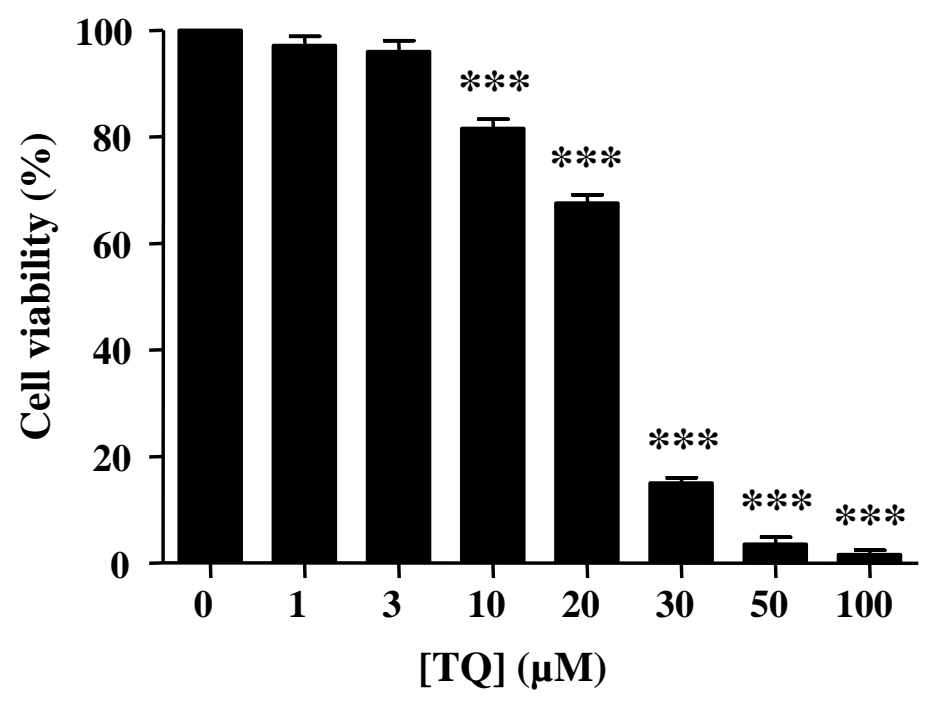

C

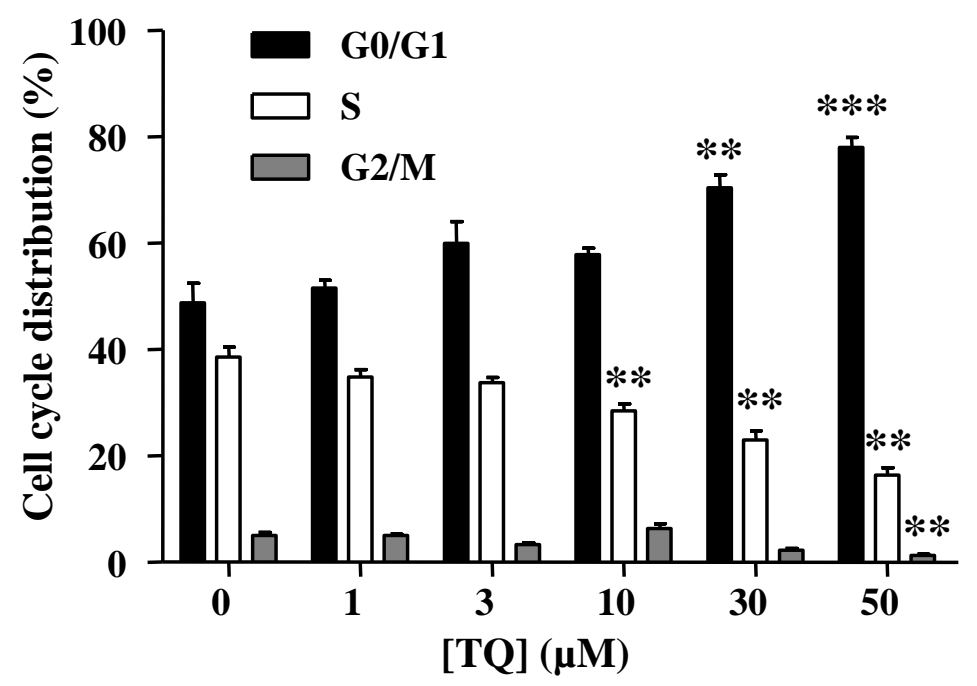

Fig. 1. 
A

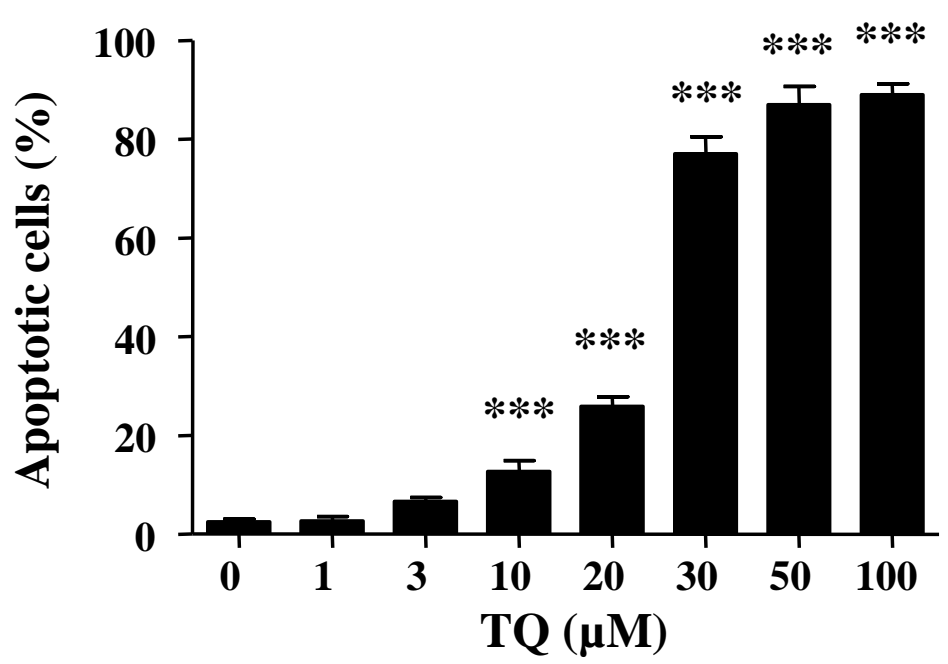

B

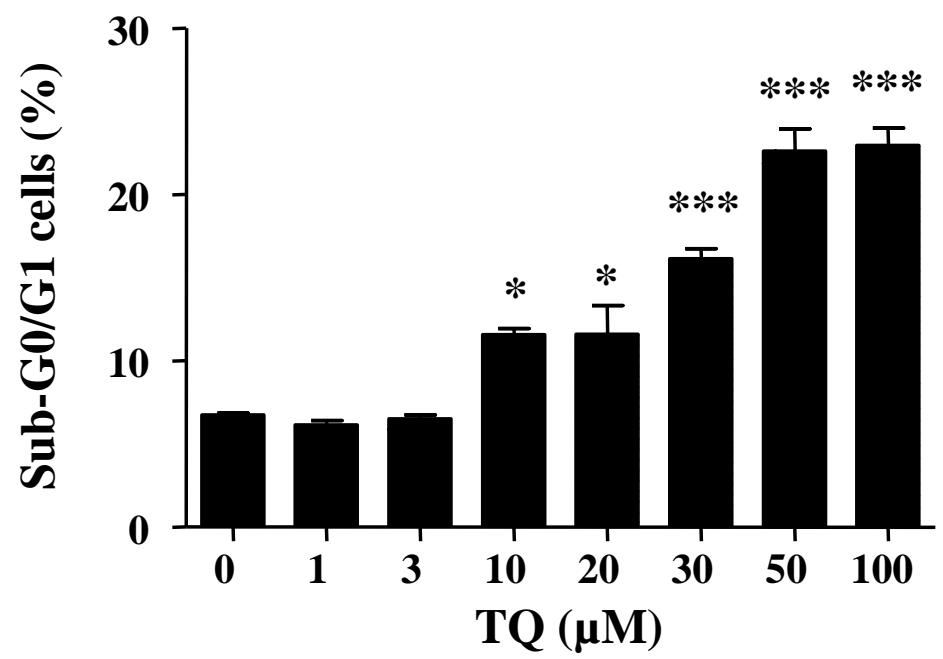

C

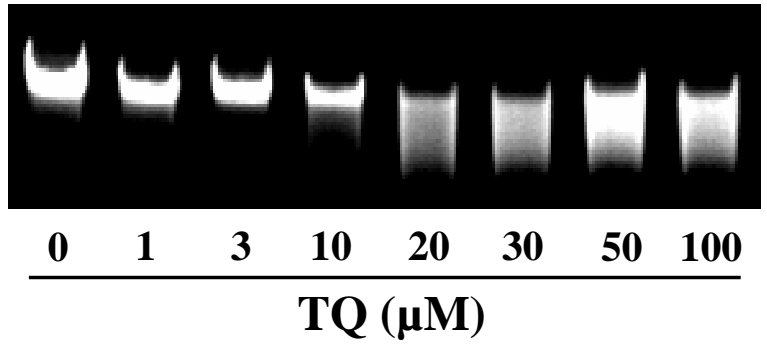

Fig. 2. 
A

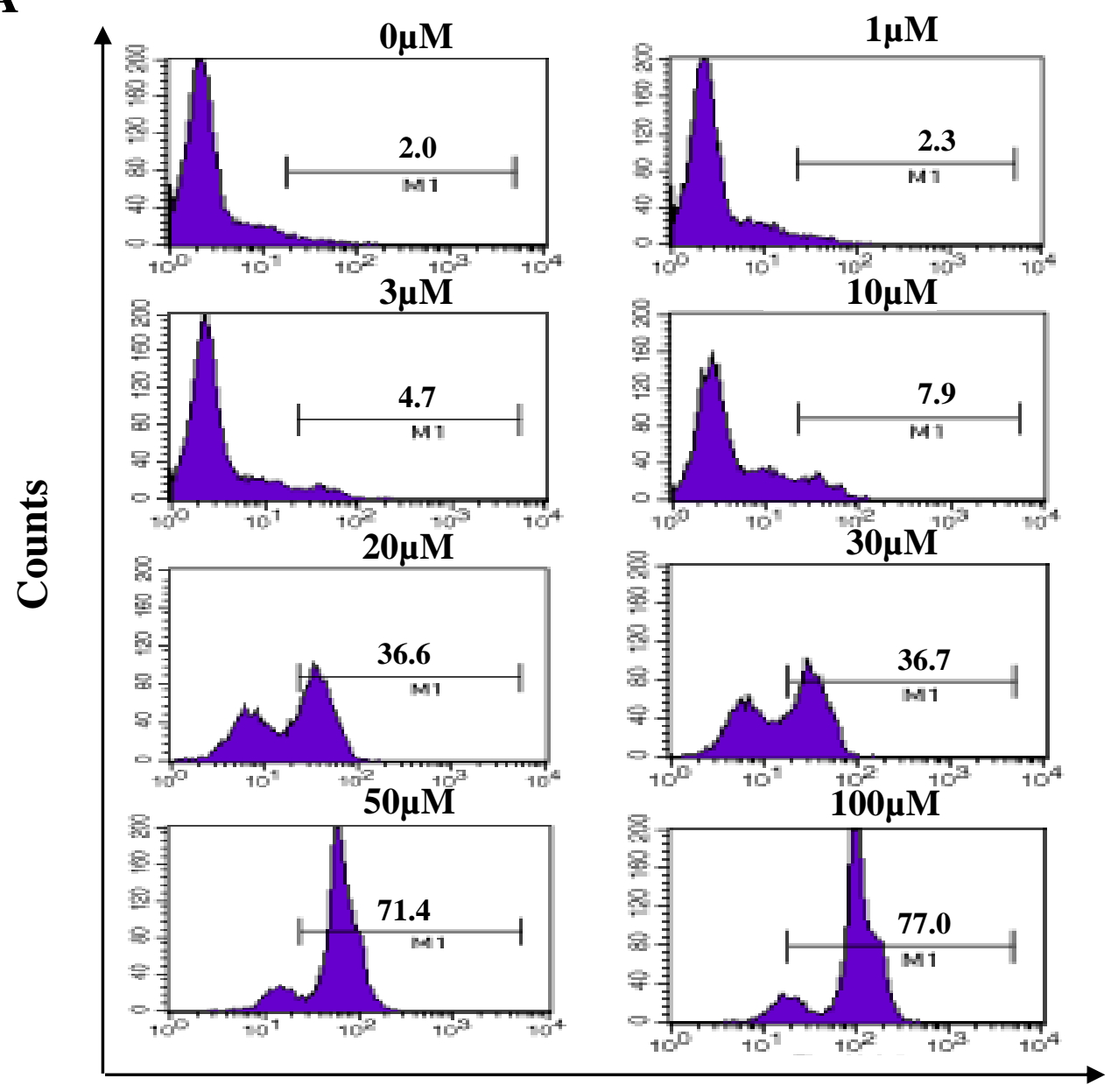

Fluorescence intensity (A.U.)

B

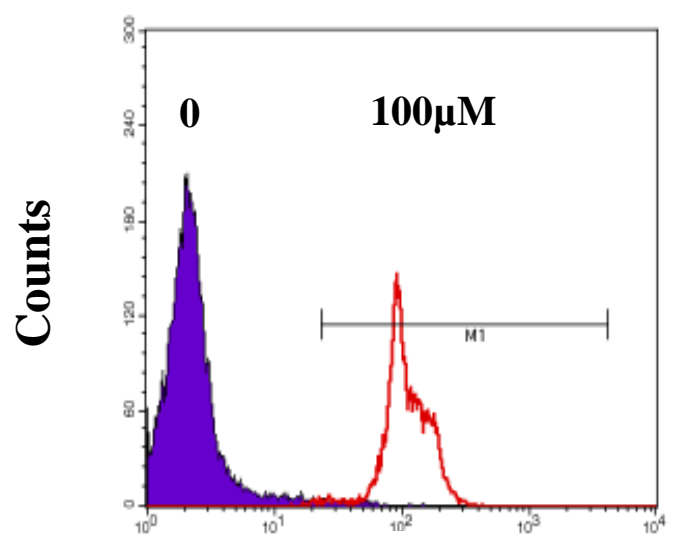

Fluorescence intensity (A.U.) 
A

B

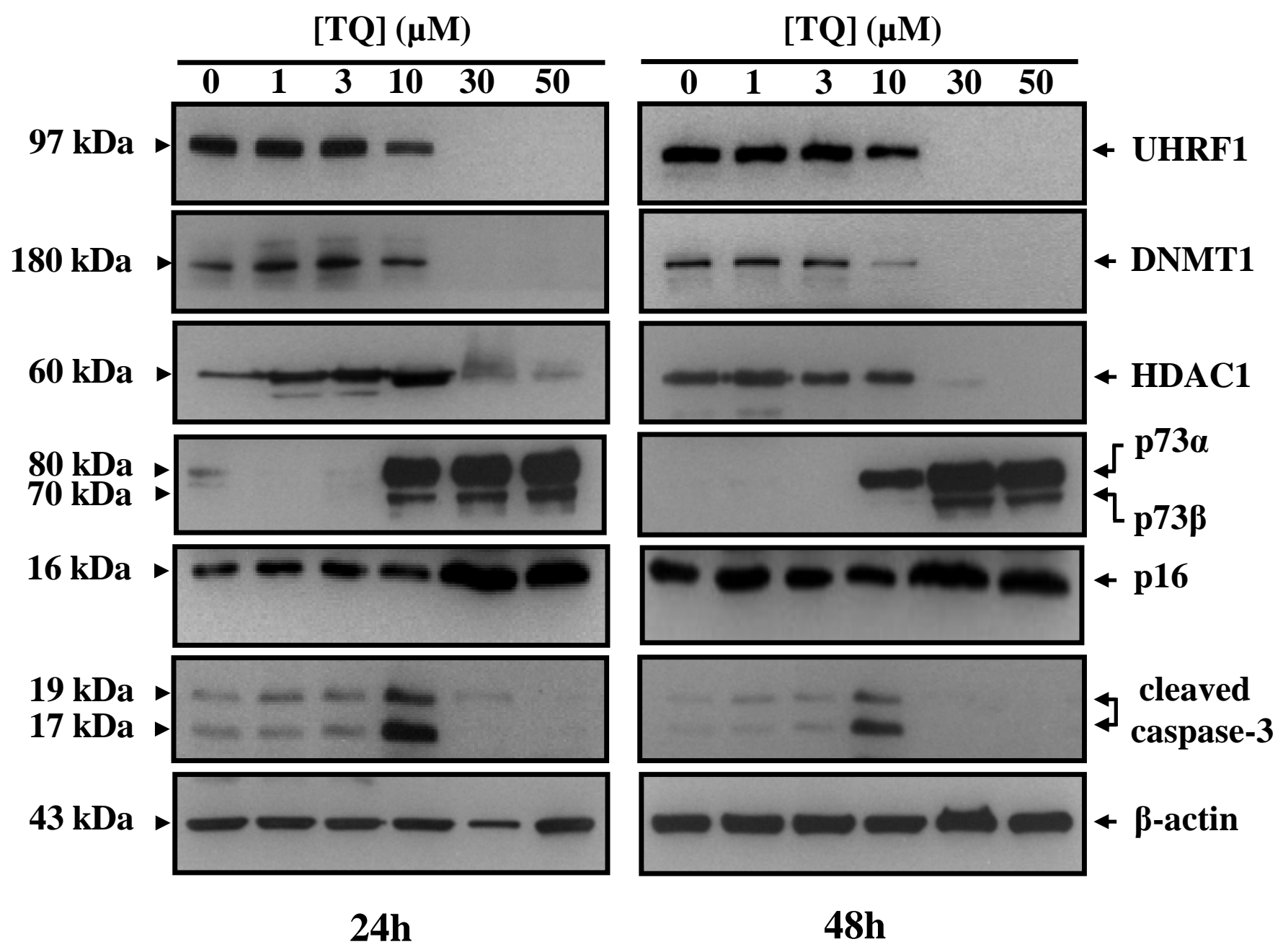

Time

Fig. 5. 
Figure 6

A

B

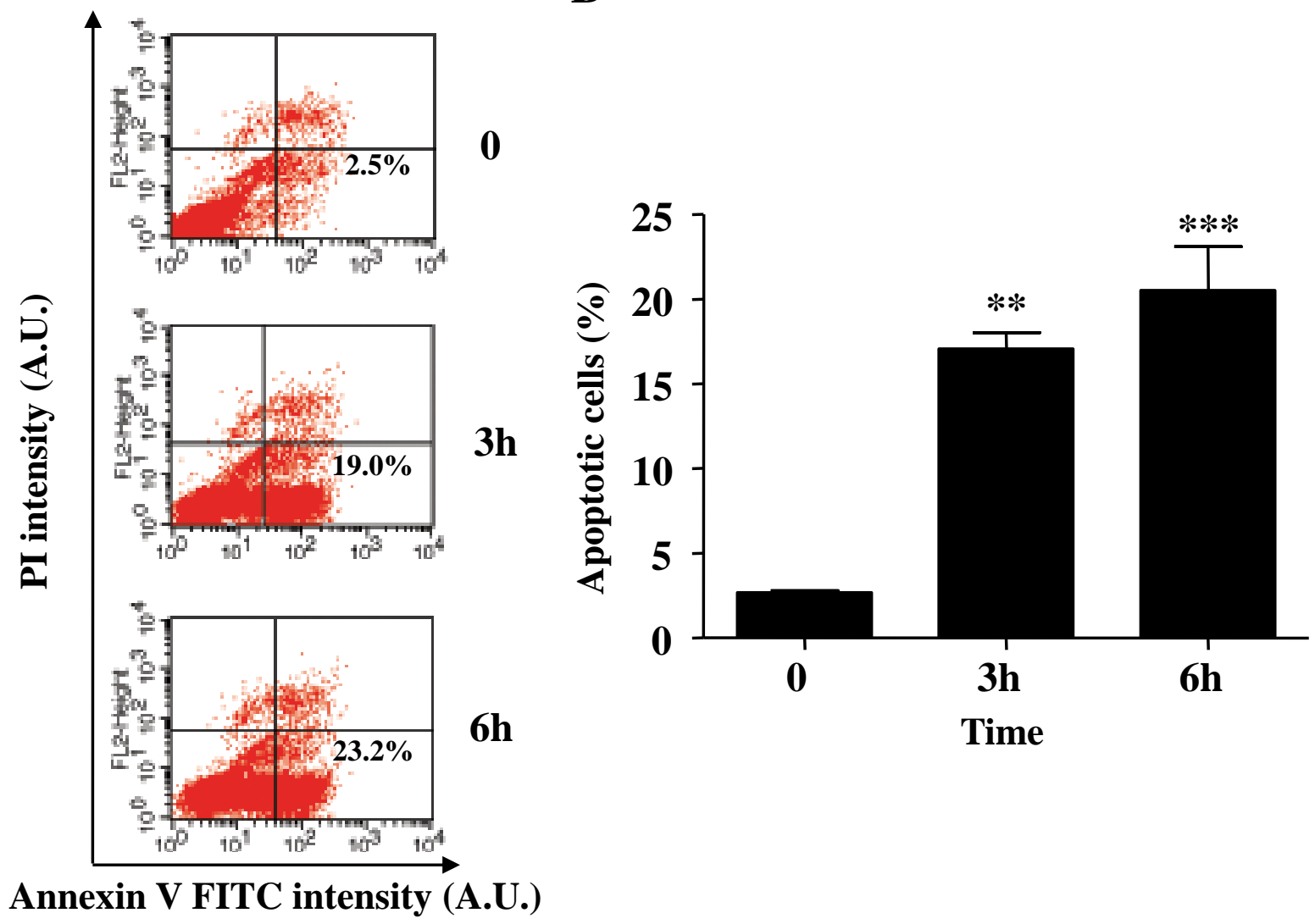

C

D

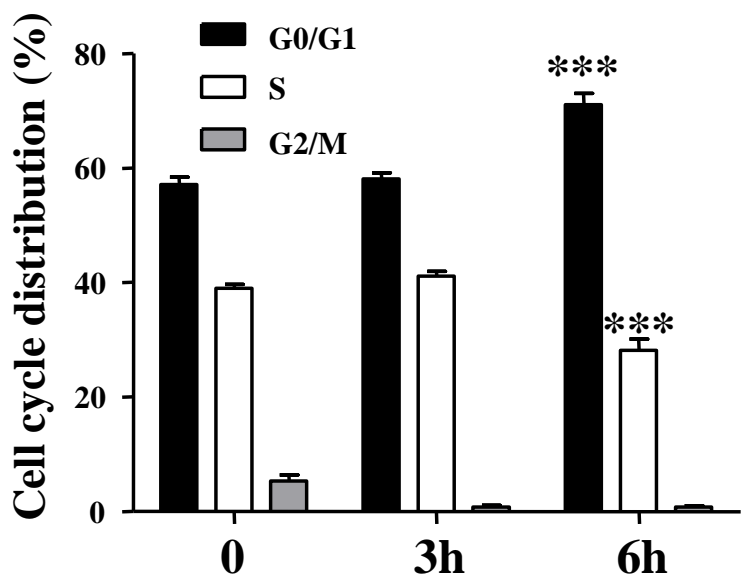

Time
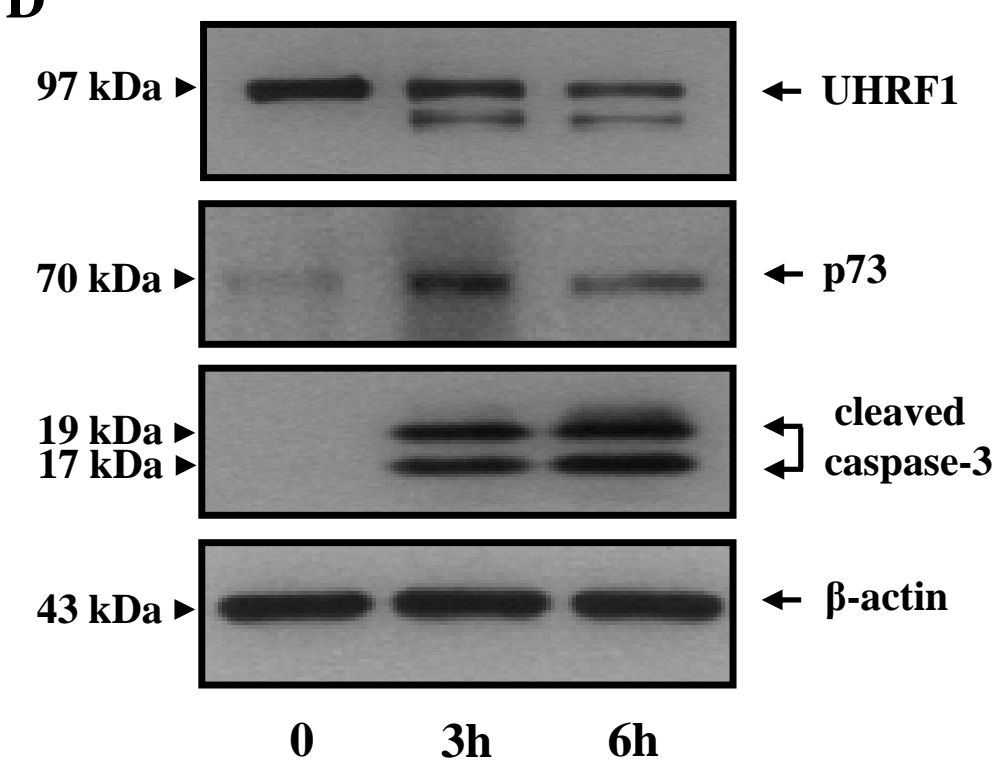

Time

Fig. 6. 

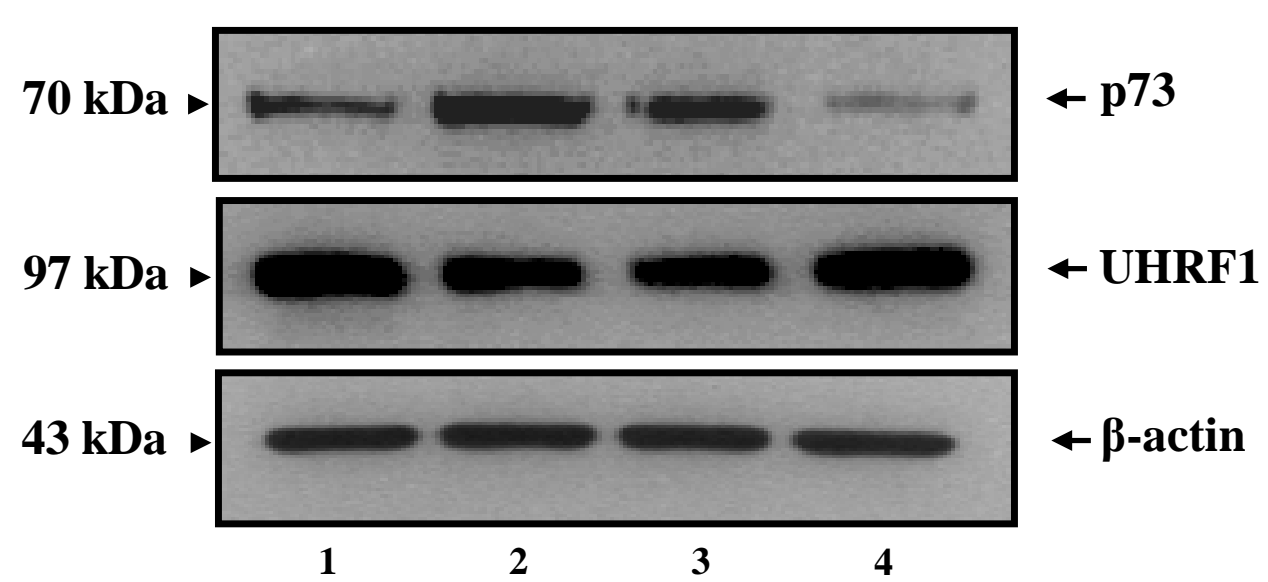

B

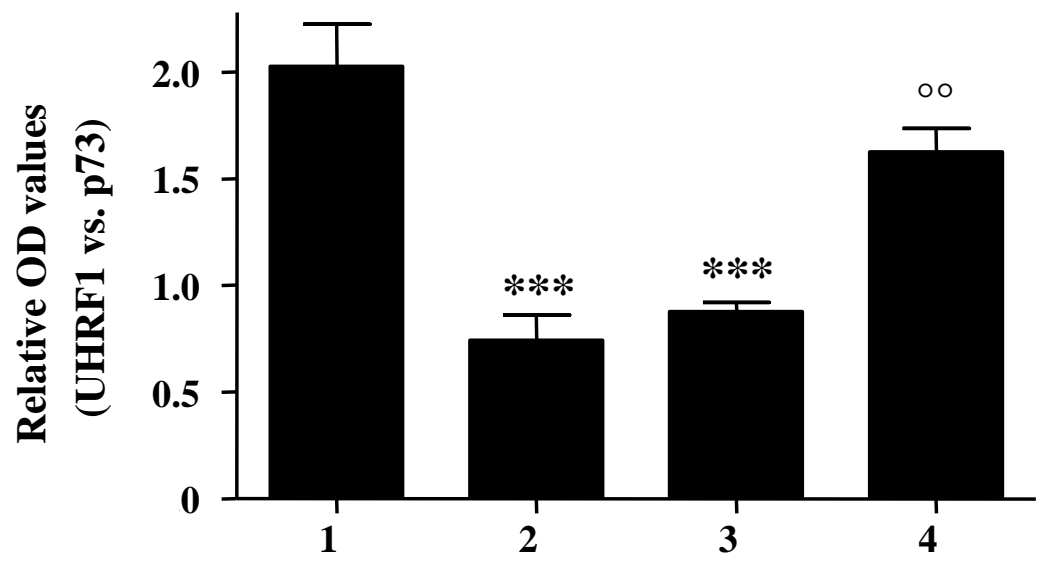

C

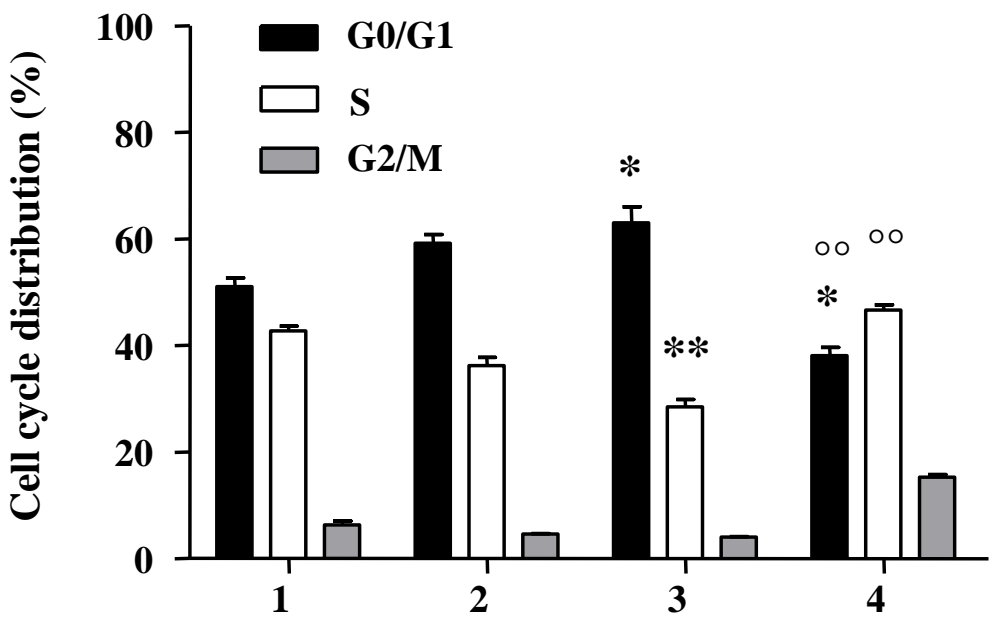

D

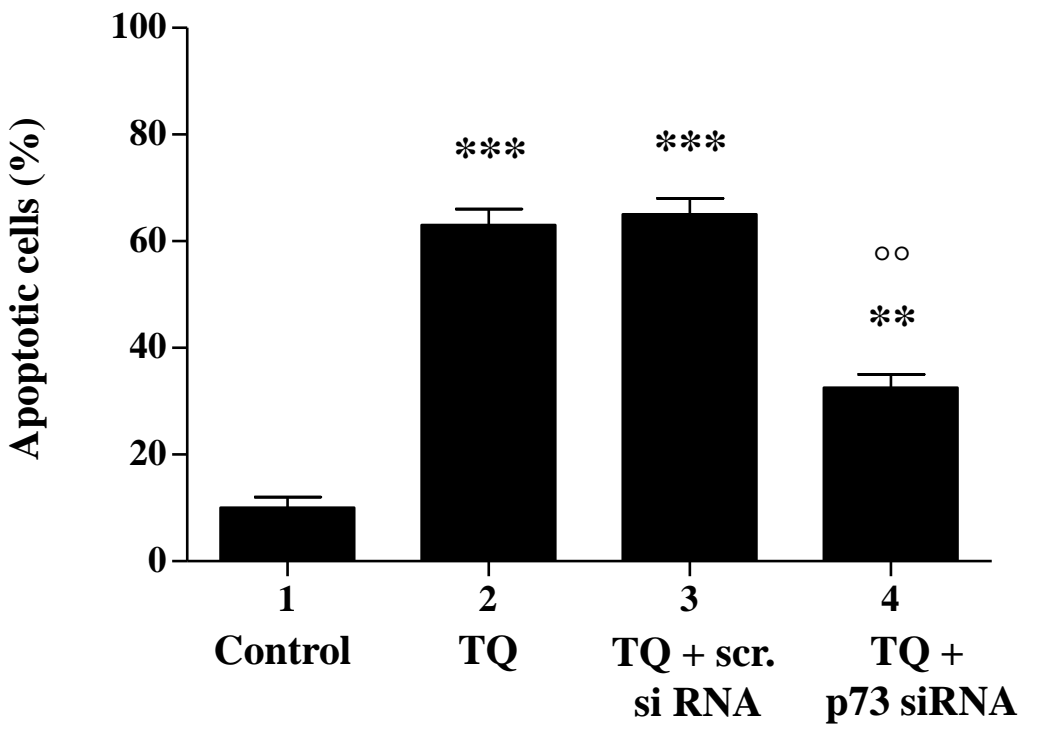

Fig. 7. 


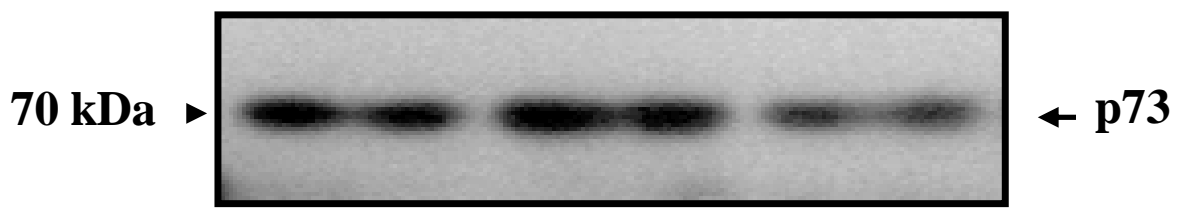

97 kDa

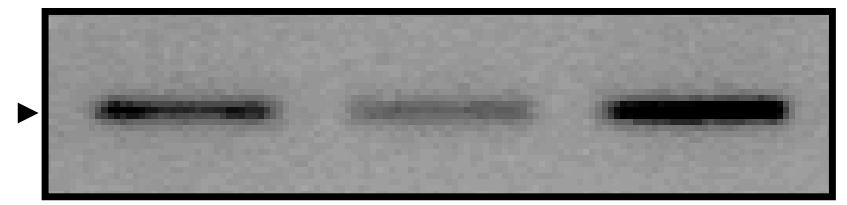

—UHRF1

43 kDa

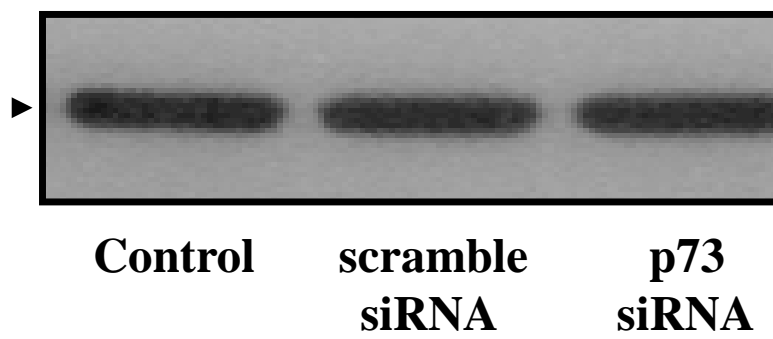

B

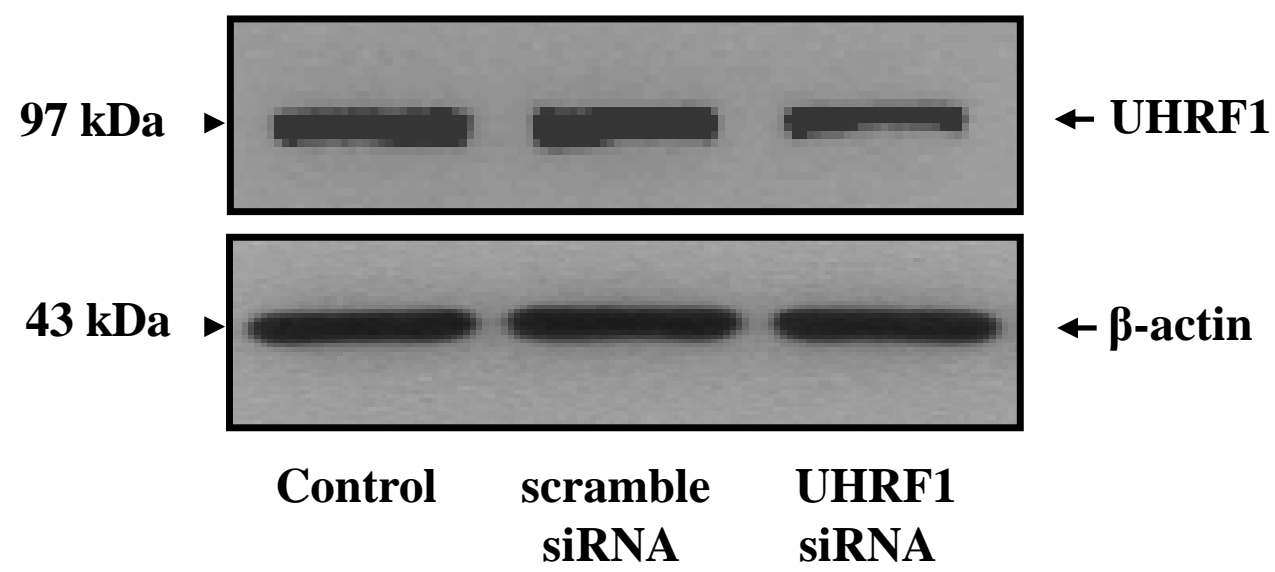

C

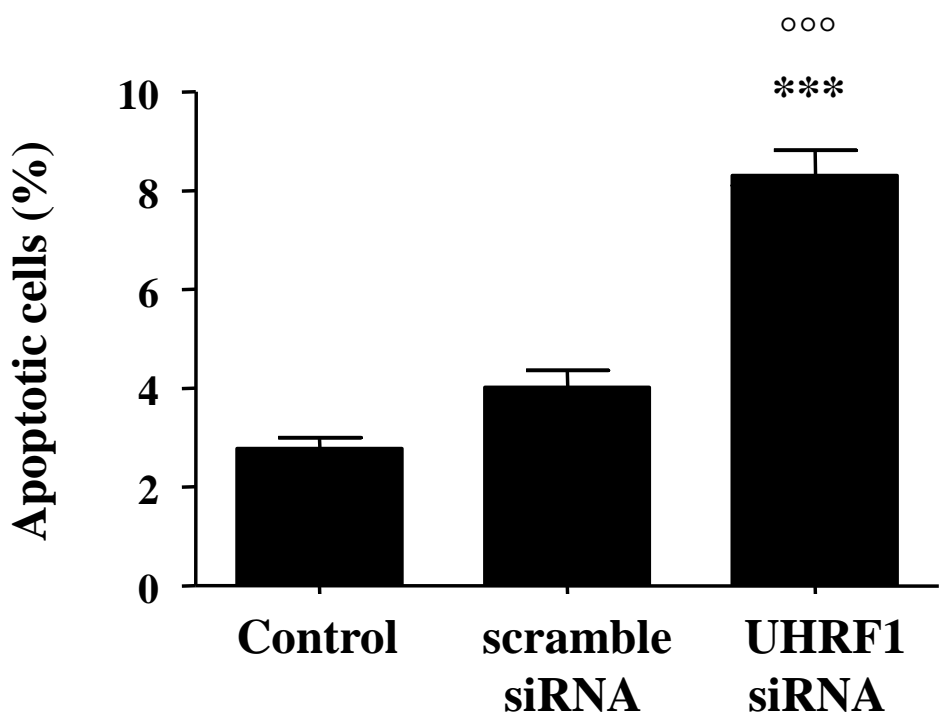

Fig. 8. 
B
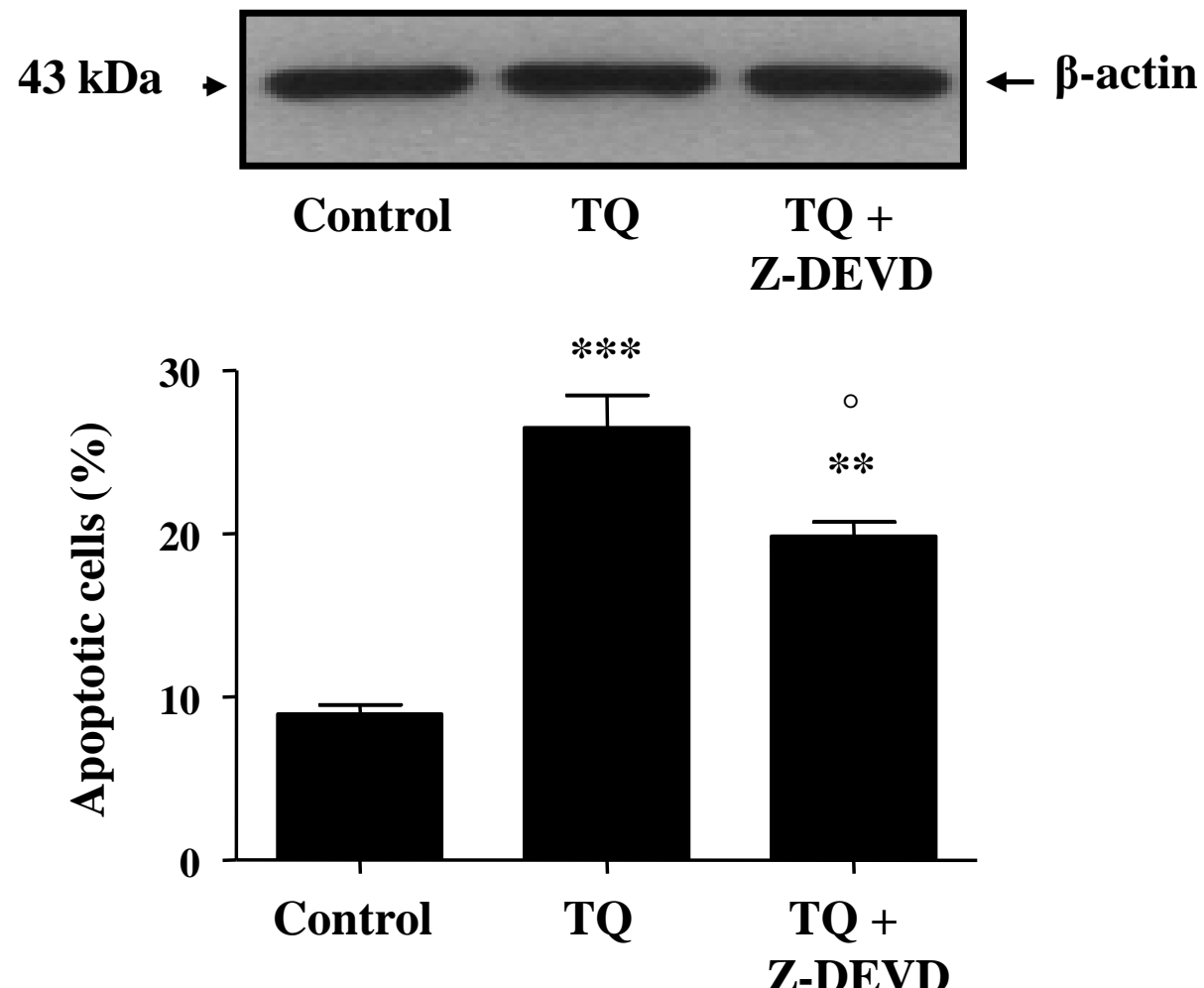

C

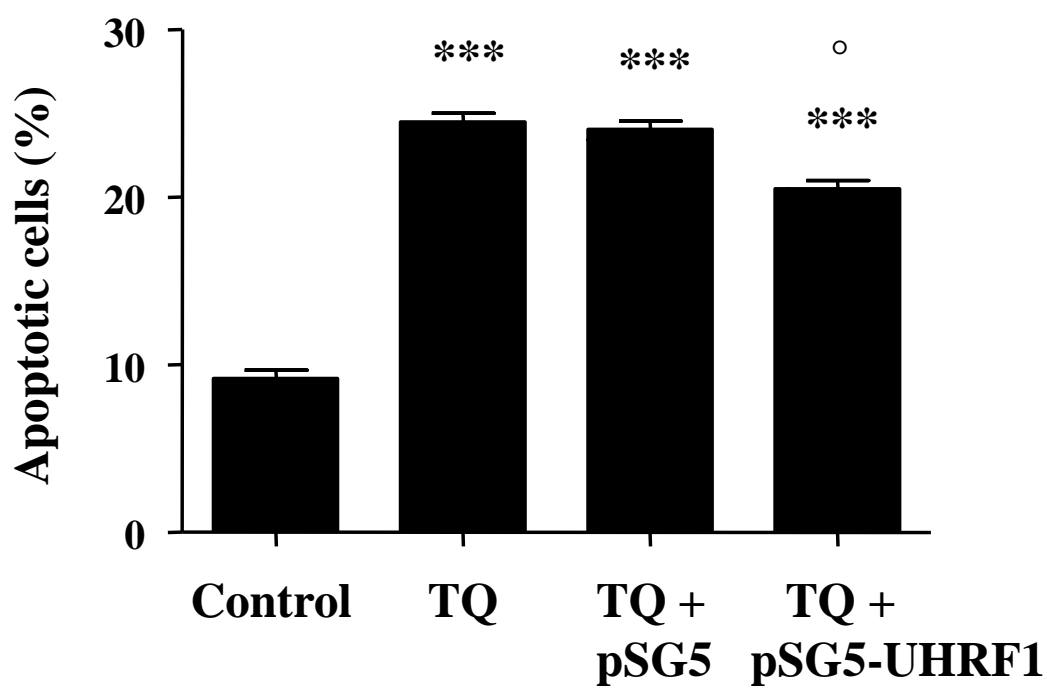

Fig. 9. 